\title{
The Renaissance of the Experimental Analysis of Human Behavior
}

\author{
Cloyd Hyten and Mark P. Reilly \\ University of North Texas
}

\begin{abstract}
Ten years ago, a number of authors commented on the dismal state of the basic research area known as the experimental analysis of human behavior (EAHB). At that time, data on the number of research articles using human subjects published in the Journal of the Experimental Analysis of Behavior (JEAB) indicated little progress since the early 1960s. However, updated publication data through 1991 reveal that EAHB research has accelerated in the last decade, reaching a peak of nearly half of all research articles published in $J E A B$, with an increasing trend evident. The increase in this percentage is not due solely to a long-term declining trend in the total number of experimental articles in $J E A B$ using either human or nonhuman subjects, a trend that appears to have slowed or stabilized in the last 6 years. These data indicate that the EAHB has made dramatic progress in a decade and is healthy and growing.
\end{abstract}

Key words: experimental analysis, human behavior, trends, human operant research, humans

A decade ago, the state of the basic research area within behavior analysis known as the experimental analysis of human behavior (EAHB) was seen by many researchers as rather dismal. Hake (1982) discussed the fact that basic human research was often seen by other basic researchers as too applied and that applied researchers saw it as too basic. He added, "This has left human operant research in a relatively weak position which is more often described as the 'crack' between basic and applied instead of the "bridge" " (p. 23). Hake summarized the state of the field: "The human operant area consists of a small number of researchers without a clear outlet for their work and with their major function being fulfilled in part by the applied researchers" (p. 23). Miller (1983) had an even more pessimistic assessment of EAHB: "What once seemed so fresh with prospect now seems never to have quite

Portions of this paper were presented in an address by the first author entitled, "The Renaissance of Human Operant Research: An Overview of RuleGoverned Behavior and Stimulus Equivalence" at the meeting of the Texas Association for Behavior Analysis, Dallas, February, 1989. We wish to thank Sigrid Glenn, Jay Moore, Gina Green, Tom Critchfield, and other anonymous reviewers for their helpful comments on earlier drafts. Correspondence may be addressed to Cloyd Hyten, Center for Behavior Analysis, P.O. Box 13438, University of North Texas, Denton, TX 76203. caught on and one is left to wonder whether EAHB is just dormant or is actually in the final abortive phases of demise" (p. 552).

Buskist and Miller (1982), and Nevin (1982) in an editorial in the Journal of the Experimental Analysis of Behavior $(J E A B)$, presented data showing the percentages of human research articles appearing in $J E A B$ through 1981 . Buskist and Miller commented on their data, "Compared to the amount of applied work published in the last 20 years, these figures paint a rather cheerless picture of experimental activity in the study of human operant behavior" (p. 139). They concluded, "It would appear from the present census that the experimental analysis of human behavior has thus far fallen short of Skinner's 'active prosecution of a science of behavior" " (p. 141). Nevin used his data to encourage EAHB submissions to $J E A B$. It is interesting to note that two seminal stimulus equivalence articles (Sidman et al., 1982; Sidman \& Tailby, 1982) appeared as lead articles in that very issue of $J E A B$.

Baron and Perone (1982), Hake (1982), and Miller (1983) offered numerous reasons for the paucity of basic behavioral research with humans, ranging from a shortage of people interested in direct investigation of human behavior (the applied area had attracted most of them), to confusion over the purpose of EAHB 
research, to practical problems such as the lack of standard research methodologies. Despite the gloomy assessments of the state of EAHB, most of these authors were optimistic about the future of EAHB. Hake went on to suggest that there was a growing community of researchers who were interested in behavioral phenomena unique to humans, and suggested that interests in verbal behavior and social behavior would revitalize the area. Buskist (1983), in an introduction to a special issue of The Psychological Record devoted to EAHB, announced that one of the purposes of the issue was to advertise some of the possible research topics and stimulate interest in the area. That articles and commentary of this kind were appearing at all was a leading indicator of a surge of interest in laboratory investigations of human behavior.

\section{RECENT PROGRESS IN EAHB}

The good news we report here is that EAHB has experienced a renaissance during the decade of the 1980 s. To assess the state of EAHB, we followed procedures similar to those used by Buskist and Miller (1982) in their summary of $J E A B$ publication data through 1981 . We counted the number of experimental articles appearing in $J E A B$ by year, distinguishing between those that used human subjects and those that used nonhuman subjects. The focus of our analysis was on articles presenting original research that used human subjects, so we excluded reviews, theoretical articles, and technical notes and articles. We did not distinguish between $J E A B$ articles that were truly "basic" in nature from those that were "applied" in nature, as Buskist and Miller did. Buskist and Miller (1982, p. 138) classified a $J E A B$ article as applied if its emphasis was on the analysis and modification of personally or socially problematic behavior rather than on the functional analysis of some aspect of the behavior per se. Articles of such an applied nature represent only a fraction of human studies in the early $J E A B$ issues, and our data differ only slightly from those of Buskist and Miller in the period between 1958-1965. As an additional consideration, we wanted to give the benefit of the doubt to such early work with human subjects at a time when the line between basic and applied research was not so clearly drawn.

We should point out that using the number of articles published in $J E A B$ is a very conservative measure of the vitality of EAHB. Despite the fact that $J E A B$ is the major journal for basic research in behavior analysis, there are other significant outlets for EAHB research, such as The Psychological Record and the growing journal The Analysis of Verbal Behavior. Occasionally, behavioral articles also appear in more mainstream psychological journals such as Learning and Motivation, although in such journals it becomes difficult to discern which articles are behavior analytic in orientation and qualify as EAHB studies. For these reasons, the conservative data presented here underestimate the amount of work in EAHB.

As noted by Buskist and Miller (1982), a substantial proportion of human experimental studies appeared in $J E A B$ during the first few years of publication (see Figure 1). The proportion of experimental publications in the area dropped during the late 1960 s and early 1970 sa virtual "dark ages" for EAHB-hovering around $5 \%$ of the total experimental articles in $J E A B$. With the exception of 1980 , there has been dramatic acceleration in this measure beginning in the late 1970 s through 1991. The peak percentage $(42.2 \%)$ occurred in 1990 , boosted by the publication of the special issue on EAHB in November of that year.

All the news is not so salutary. Figure 2 shows the total number of experimental articles appearing in $J E A B$ 1958-1991, as well as the separation of these data into the constituent numbers of human and nonhuman experimental articles. Regarding the total number of experimental articles (the sum of both human and nonhuman research articles), Nevin (1982) presented similar data showing that this measure reached a zenith in the early 1970s. As of Nevin's 1981 data, an ominous decreasing trend appeared to be 


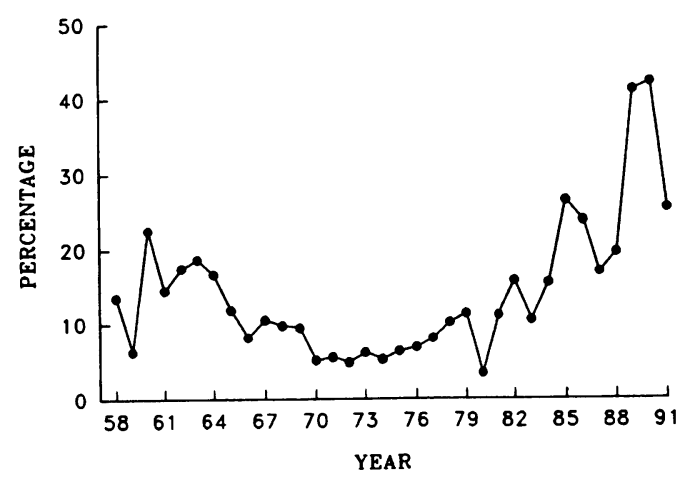

Figure 1. The percentage of experimental articles in $J E A B$ that used human subjects 1958-1991.

continuing; however, our updated data show that this has at least slowed and perhaps stabilized in the last 6 years. Nevin suggested that these data revealed a declining interest in behavioral research during the late 1970 s, presumably because of a growing interest in cognitively oriented research. If this is true, then the data indicate that the so-called cognitive revolution appears to have taken its toll primarily on behavioral research with nonhuman subjects. Other factors may have contributed to the decline in nonhuman research. A full treatment of this topic is beyond the scope of this paper, but several authors (e.g., Dinsmoor, 1991; Hayes, Zettle, \& Rosenfarb, 1989; Lattal, McFarland, \& Joyce, 1990) have put forth various reasons why nonhuman research has become more difficult to do recently; these include the increased costs of animal facilities required to meet revised specifications, more restrictive guidelines regarding animal rights and research topics, reductions in grant funding for nonhuman research, and resulting difficulties in obtaining or keeping jobs for researchers in this area.

Figure 2 indicates that the lowest percentages of EAHB articles seen in Figure 1 were due in part to the proportionally large number of nonhuman experimental studies appearing during the late 1960s and early 1970 s. One might erroneously conclude that the recent increase in the proportion of EAHB studies seen in Figure 1 is merely an artifact of declining nonhuman studies. However, although

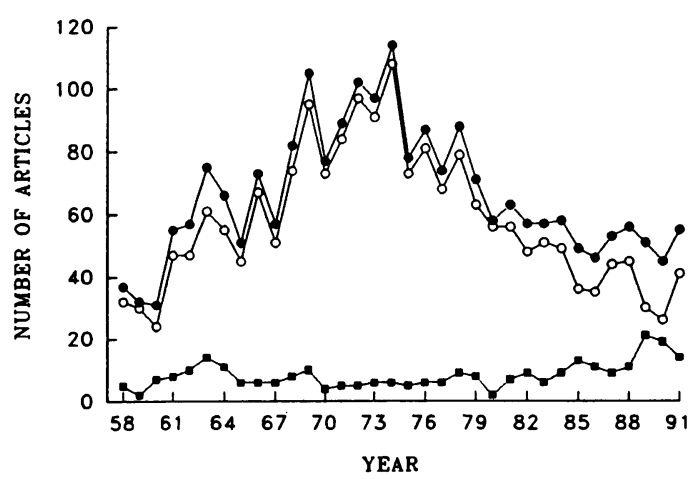

Figure 2. The number of experimental articles in $J E A B$ by year. Filled circles are the total number of all experimental articles (using either human or nonhuman subjects), open circles are the number of experimental articles using nonhuman subjects, and filled squares are the number of articles using human subjects.

the declining trend in nonhuman studies amplifies the percentage of human studies, Figure 2 reveals that the raw number of EAHB articles does show an increasing trend. To accommodate the total number of experimental articles, the scale of Figure 2 necessarily compresses the variability in the measure of EAHB articles, obscuring a detailed portrait of these data. Figure 3 presents the data on the number of EAHB articles rescaled to permit a closer examination of the variability and trends. It is apparent that the recent increasing trend represents a twofold to fourfold increase over the numbers seen in the mid-1970s.

Ironically, the cognitive revolution may also be partly responsible for the increase in EAHB research in the last decade. We suspect that the rise of interest in cognition and cognitive theory that exploded in the late 1970s stimulated many behavior analysts to take a second look at research on human behavior within the field of behavior analysis. What behavior analysts saw was much talk and assurance that behavioral principles could account for complex human behavior, but they found little direct support from the basic research laboratory (Lowe, 1979, pp. 159-160; also see the historical overviews of this period by Hayes et al., 1989, pp. 191-195, and by M. Vaughan, 1989, pp. 107-108). The strong criticisms coming from the cognitivists about the in- 


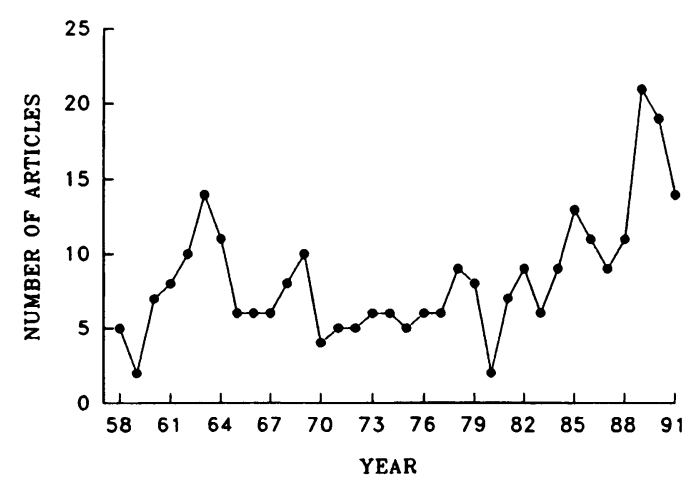

Figure 3. The number of experimental articles in $J E A B$ that used human subjects 1958-1991.

adequacy of behavioral theory in explaining human behavior may have functioned as an establishing operation (Michael, 1982), making interest and involvement in EAHB research suddenly more reinforcing.

The editorial policies and practices of $J E A B$ supported this increased involvement in EAHB. Editorials by John Nevin (1982) and Edmund Fantino (1988) during their terms as Editor (Nevin: 1980 1983; Fantino: 1988-1991) explicitly called for submissions in EAHB (among other areas). Philip Hineline's editorial term (1984-1987) was also marked by support of EAHB and frequent placement of EAHB articles in the prominent lead position in $J E A B$ issues. Figures 1 and 3 show that it was during the editorial terms of these three editors that EAHB experienced its upsurge, and they and their Associate Editors deserve credit for their substantial support of both the quantity and quality of EAHB articles.

Two profitable lines of research have appeared and become major topics in EAHB: rule-governed behavior, or instructional control, and the area of conditional discrimination known as stimulus equivalence (Navarick, Bernstein, \& Fantino, 1990). As Hake (1982) predicted, these two areas involve phenomena that appear to be unique to humans (this is disputed in the case of stimulus equivalence; see Hayes, 1989a; McIntire, Cleary, \& Thompson, 1989; Saunders, 1989; W. Vaughan, 1989). Work in these areas continues with the regular appearance of stimulus equivalence articles in
$J E A B$ and publication of the first major book devoted solely to rule-governed behavior (Hayes, 1989b).

We have not classified the research articles in $J E A B$ by topic area, but it is apparent that current EAHB research covers more than rule-governed behavior and stimulus equivalence. In the last 2 years, for example, EAHB articles have appeared in $J E A B$ on such diverse topics as drug effects in humans, choice and selfcontrol, verbal self-reports, aggressive behavior, behavioral momentum, memory in older adults, and leadership, to name a few. In short, the EAHB area is healthy and growing. From the vantage point of 1992, the condition of the field is vastly improved over the state of affairs a mere decade ago. The experimental analysis of human behavior has become a major element of basic behavioral research.

An additional indicator of the vitality of EAHB is the rapid growth of the EAHB Special Interest Group (SIG) of the Association for Behavior Analysis (McIlvane \& Saunders, 1991), which publishes the Experimental Analysis of Human Behavior Bulletin. In 1991, the membership of the SIG voted to discontinue the practice of holding special group poster sessions for EAHB data at the Association for Behavior Analysis convention. Paradoxically, the main reason for this decision was that the poster sessions, the original purpose of which was to stimulate interest in EAHB research, had become a dramatic success! The number of EAHB posters had become so large in recent years that they were unwieldy to schedule, and many members felt that a special effort to promote EAHB research was no longer needed.

\section{CONCLUSIONS}

The data presented in this article indicate a renaissance of interest and research in EAHB. We do not believe these data imply that there has been a breakthrough in either theoretical or methodological realms that has permitted this growth, at least in the sense of there being resolutions of longstanding problems and 
questions. Researchers have not come to a consensus on methods, theories, or future directions in EAHB. In fact, there is much lively debate and thoughtful discussion on these issues (see, e.g., the questioning of fundamental assumptions guiding research by Hayes, 1987; the series of articles in this journal on laboratory lore and experimental methods introduced by Buskist \& Johnston, 1988; and the series on the role of EAHB in behavior analysis based on the target article by Baron, Perone, \& Galizio, 1991). This is a dynamic time for EAHB; indeed, some (Hayes, 1987) have characterized it as a revolutionary period. Our interpretation of the data we present here is that researchers have begun to address these issues and are currently struggling with them. Resolutions of major issues, such as the nature and determinants of the interaction between verbal and nonverbal behavior, the utility of current formulations of basic principles for the explanation and control of human behavior, and the development of improved research methods with which to examine such questions, await many more years of effort.

If present trends continue, basic research with human subjects may exceed $50 \%$ of $J E A B$ articles sometime in the 1990s. Whether such an event would bode well for the overall health of behavior analysis may be open to dispute (particularly if it occurs because nonhuman laboratories close down), but no one could deny that the statement, "The majority of basic research in behavior analysis uses human subjects," would mark a significant change in the field. It would certainly be a salient signal to those outside of behavior analysis that this field is actively committed to pursuing the investigation of human behavior.

\section{REFERENCES}

Baron, A., \& Perone, M. (1982). The place of the human subject in the operant laboratory. The Behavior Analyst, 5, 143-158.

Baron, A., Perone, M., \& Galizio, M. (1991). Analyzing the reinforcement process at the human level: Can application and behavioristic interpretation replace laboratory research? The $\mathrm{Be}$ havior Analyst, 14, 95-105.
Buskist, W. F. (1983). Introduction. The Psychological Record, 33, 451-456.

Buskist, W. F., \& Johnston, J. M. (1988). Laboratory lore and research practices in the experimental analysis of human behavior. The Behavior Analyst, 11, 41-42.

Buskist, W. F., \& Miller, H. L. (1982). The analysis of human operant behavior: A brief census of the literature: 1958-1981. The Behavior Analyst, 5, 137-141.

Dinsmoor, J. A. (1991). The respective roles of human and nonhuman subjects in behavioral research. The Behavior Analyst, 14, 117-121.

Fantino, E. (1988). Editorial. Journal of the Experimental Analysis of Behavior, 49, 1-2.

Hake, D. F. (1982). The basic-applied continuum and the possible evolution of human operant social and verbal research. The Behavior Analyst, $5,21-28$.

Hayes, S. C. (1987). Upward and downward continuity: It's time to change our strategic assumptions. Behavior Analysis, 22, 3-6.

Hayes, S. C. (1989a). Nonhumans have not yet shown stimulus equivalence. Journal of the Experimental Analysis of Behavior, 51, 385-392.

Hayes, S. C. (Ed.). (1989b). Rule-governed behavior: Cognition, contingencies, and instructional control. New York: Plenum.

Hayes, S. C., Zettle, R. D., \& Rosenfarb, I. (1989). Rule-following. In S. C. Hayes (Ed.), Rule-governed behavior: Cognition, contingencies, and instructional control (pp. 191-220). New York: Plenum.

Lattal, K. A., McFarland, J. M., \& Joyce, J. H. (1990). What is happening in psychology of learning courses? The Behavior Analyst, 13, 121130.

Lowe, C. F. (1979). Determinants of human operant behaviour. In M. D. Zeiler \& P. Harzem (Eds.), Advances in analysis of behaviour: Vol. 1. Reinforcement and the organization of behaviour (pp. 159-192). Chichester, England: Wiley.

McIlvane, W. J., \& Saunders, K. J. (1991). Editorial. Experimental Analysis of Human Behavior Bulletin, 9, 19-20.

McIntire, K. D., Cleary, J., \& Thompson, T. (1989). Reply to Saunders and to Hayes. Journal of the Experimental Analysis of Behavior, 51, 393-396.

Michael, J. (1982). Distinguishing between discriminative and motivational functions of stimuli. Journal of the Experimental Analysis of Behavior, 37, 149-155.

Miller, H. L. (1983). More than promissory? Reflections on the once and future experimental analysis of human behavior. The Psychological Record, 33, 551-564.

Navarick, D., Bernstein, D., \& Fantino, E. (1990). The experimental analysis of human behavior. Journal of the Experimental Analysis of Behavior, $54,159-162$.

Nevin, J. A. (1982). Editorial. Journal of the Experimental Analysis of Behavior, 37, 1-2.

Saunders, K. J. (1989). Naming in conditional discrimination and stimulus equivalence. Journal of the Experimental Analysis of Behavior, 51, 379-384. 
Sidman, M., Rauzin, R., Lazar, R., Cunningham, S., Tailby, W., \& Carrigan, P. (1982). A search for symmetry in the conditional discrimination of rhesus monkeys, baboons, and children. Journal of the Experimental Analysis of Behavior, 37, 23-44.

Sidman, M., \& Tailby, W. (1982). Conditional discrimination vs. matching to sample: An expansion of the testing paradigm. Journal of the Experimental Analysis of Behavior, 37, 5-22.
Vaughan, M. (1989). Rule-governed behavior in behavior analysis: A theoretical and experimental history. In S. C. Hayes (Ed.), Rule-governed behavior: Cognition, contingencies, and instructional control (pp. 97-118). New York: Plenum. Vaughan, W. (1989). Reply to Hayes. Journal of the Experimental Analysis of Behavior, 51, 397. 